\title{
Structure-based evaluation of the resonance interactions and effectiveness of the charge transfer in nitroamines
}

\author{
Ryszard Gawinecki • Erkki Kolehmainen • \\ Robert Dobosz
}

Received: 29 March 2011 / Accepted: 27 June 2011 / Published online: 13 July 2011

(C) The Author(s) 2011. This article is published with open access at Springerlink.com

\begin{abstract}
Structural data for five nitroamines of general formula $\mathrm{Me}_{2} \mathrm{~N}-\mathrm{G}-\mathrm{NO}_{2}$ show effectiveness of the groundstate charge transfer to be most and least efficient in $N, N$-dimethylnitramine and in 4- $N, N$-dimethylamino- $\beta$ nitrostyrene, respectively. Electron-donor power of the amino nitrogen atom in the latter compound is less than that in 4-nitro- $\beta-N, N$-dimethylaminostyrene (these two compounds are isomers). Natural population analysis shows that the charge transfer from the amino to the nitro oxygen atoms is most effective in $\mathrm{N}, \mathrm{N}$-dimethylnitramine, $\mathrm{Me}_{2} \mathrm{~N}-\mathrm{NO}_{2}$. The nitro oxygen atoms are not the only acceptors of the negative charge lost by the amino nitrogen atom. The nitro group in two substituted nitrobenzenes studied was found to be independent on substituent (nitro group attached to the benzene ring withdraws a constant electron density regardless the substitution).
\end{abstract}

Keywords Nitroamines - Resonance interaction - Charge transfer · Molecular structure - Quantum-chemical calculations

\section{Introduction}

Numerous properties of the conjugated push-pull systems, e.g. basicities, dipole moments, and spectral parameters, are significantly affected by the intramolecular charge

R. Gawinecki $(\bowtie) \cdot$ R. Dobosz

Department of Chemistry, University of Technology and Life

Sciences, Seminaryjna 3, 85-326 Bydgoszcz, Poland

e-mail: gawiner@utp.edu.pl

E. Kolehmainen

Department of Chemistry, University of Jyväskylä, P.O. Box 35, 40014 Jyväskylä, Finland transfer [1]. A series of such compounds has been recently studied by us [2]. Since nitro and amino groups are among the most common acceptors and donors known, nitramines $\mathrm{R}_{2} \mathrm{~N}-\mathrm{NO}_{2}$ are subjected to extremely effective electron transfer. For this reason, intramolecular interactions in these compounds have often been studied [3-7]. $p$-Nitroanilines also contain these two strongly interacting groups where they are separated by the $p$-phenylene moiety. There is a question about the effect of conjugated spacers on the charge transfer in compounds of general formula $\mathrm{R}_{2} \mathrm{~N}-\mathrm{G}-\mathrm{NO}_{2}$. This problem has been studied only occasionally. Thus, comparison of the dipole moments and spectral (IR and UV-vis) parameters for $\mathrm{Me}_{2} \mathrm{~N}-\mathrm{NO}_{2}$ and $p-\mathrm{Me}_{2} \mathrm{~N}-\mathrm{C}_{6} \mathrm{H}_{4}-\mathrm{NO}_{2}$ was found helpful to prove that the said interaction is really weaker when the $\mathrm{NMe}_{2}$ and $\mathrm{NO}_{2}$ groups are separated with the system of conjugated $\pi$ bonds [8,9]. Effective intramolecular charge transfer in the molecules of 4- $N, N$-dimethylamino- $\beta$-nitrostyrene is responsible for their stacking in dimers and tetramers with antiparallel dipoles [10].

The very basic concept of intramolecular charge transfer from the amino to the nitro groups in nitroamines [11, 12] has been criticized [13, 14]. Relatively low values of the net $\pi$-electron population in the molecule $[15,16]$ and unexpectedly low contribution ( $12.7 \%$ for $N, N$-diethyl- $p$ nitroaniline, based on X-ray data) of the full through-resonance structure $\mathbf{G}$ (Scheme 1) [13] are in line with this criticism. On the other hand, it was shown for $R=E t$ that, at least in the crystalline state, other structures presented in Scheme 1 were found to be more important [13]. Valence bond description gives some support to this idea: negative charge from the amino group in $p$-nitroaniline is transferred to the benzene ring but not to the nitro group [14].

Although structural (X-ray and electron diffraction) data for nitroamines of general formula $\mathrm{R}_{2} \mathrm{~N}-\mathrm{G}-\mathrm{NO}_{2}$ are available for $\mathrm{G}$ being none, trans $-\mathrm{CH}=\mathrm{CH}-$, 


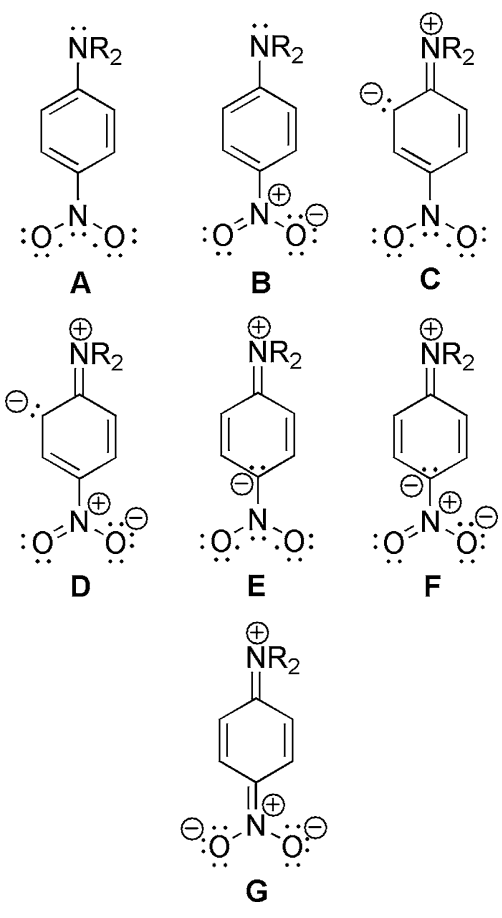

Scheme 1 Resonance structures of $p$-nitroanilines

$p-\mathrm{C}_{6} \mathrm{H}_{4}-, \quad p-\mathrm{C}_{6} \mathrm{H}_{4}-\mathrm{CH}=\mathrm{CH}$-trans, and trans $-\mathrm{CH}=\mathrm{CH}-$ $\mathrm{C}_{6} \mathrm{H}_{4}-p[8,10,17-25,9]$, these parameters have not practically been used to study the ground-state charge transfer in their molecules. Thus, we found it reasonable to examine usefulness of these data in learning the effect of the conjugated spacer on nature and effectiveness of the interaction between the amino and nitro groups. This effect will be additionally evaluated from the point of view of natural population analysis. Present studies are expected to help to understand the properties of nitroamines. For the sake of convenience, numbers of atoms present in the common molecular fragments of 1-5 were always the same (Scheme 2).

\section{Results and discussion}

The literature data show that $N, N$-dimethylnitramine, $\mathbf{1}$, is planar both in the crystal and gas states $[17,18]$. Length of the $\mathrm{N}-\mathrm{N}$ bond $(126 \mathrm{pm})$ proves that it has significantly double-bond character [8, 17, 9]. In the crystal state, the $\mathrm{C} 2-\mathrm{C} 3$ and $\mathrm{C} 5-\mathrm{C} 6$ bonds in the molecule of $N, N$-dimethyl$p$-nitroaniline, $\mathbf{3}$, are significantly shorter than other bonds in the ring $[19,20]$. The $\mathrm{C} 1-\mathrm{N} 18$ and $\mathrm{C} 4-\mathrm{N} 15$ bonds in the compounds studied are shorter as compared with the average values for $\mathrm{C}_{\mathrm{Ar}}-\mathrm{NO}_{2}$ and $\mathrm{C}_{\mathrm{Ar}}-\mathrm{NMe}_{2}$ distances [21]. Thus, there is a significant quinoid contribution to the electronic structure of $N, N$-dimethyl- $p$-nitroaniline.

C7-C 8 bond lengths in $\mathbf{2}$ and $\mathbf{4}$ (Table 1) are comparable. On the other hand, that bond in $\mathbf{5}$ is much shorter. This proves that charge transfer in $\mathbf{5}$ is less effective than in 2 and 4. Although the bonds between the amino nitrogen and alkene or aromatic carbon atoms, i.e. C4-N15, $\mathrm{C} 8-\mathrm{N} 15, \mathrm{C} 12-\mathrm{N} 15$, in $\mathbf{3}, \mathbf{4}$, and $\mathbf{5}$ are comparable, this bond in $\mathbf{2}$ is visibly shorter. Thus, the charge transfer in $\mathbf{2}$ is more effective than in $\mathbf{3}, \mathbf{4}$, and $\mathbf{5}$. This conclusion is supported by longer bonds between the nitro nitrogen and alkene or aromatic carbon atoms (C1-N18, C7-N18) in 3, $\mathbf{4}$, and $\mathbf{5}$ as compared to this in $\mathbf{2}$.

Delocalization of the lone electron pair of N15 shortens the N15-C 8 bond in $\mathbf{4}$ and $\mathbf{5}$ (crystalline state) to $135.9 \mathrm{pm}$ (it is much shorter than the standard single $\mathrm{N}-\mathrm{C}$ bond) [10, $21,23]$. The molecule of $4-N, N$-dimethylamino- $\beta$-nitrostyrene, $\mathbf{5}$, is almost planar, indicating significant conjugation between the amino and nitro groups [10]. Analysis of the bond lengths supports significant quinoid character of the six-membered ring in this compound. The C13-C14 $(139.0 \mathrm{pm})$ and $\mathrm{C} 10-\mathrm{C} 11(137.3 \mathrm{pm})$ bonds in $\mathbf{5}$ are significantly shorter than $\mathrm{C} 12-\mathrm{C} 13$ (141.8 pm), C12C11 (142.3 pm), C14-C9 (140.45 pm), and C9-C10 (140.57 pm). For the above mentioned reason, C9-C8 bond in this compound $(144.8 \mathrm{pm})$ is shorter than the standard single $\mathrm{C}-\mathrm{C}$ bond [10]. One should pay attention to asymmetry of the benzene rings in compounds $\mathbf{4}$ and $\mathbf{5}$ (the lines passing by $\mathrm{C} 1$ and $\mathrm{C} 4$ and by $\mathrm{C} 9$ and $\mathrm{C} 12$ are not their symmetry axes) which is a result of the asymmetry of the $\mathrm{CH}=\mathrm{CH}-\mathrm{NMe}_{2}$ and $\mathrm{CH}=\mathrm{CH}-\mathrm{NO}_{2}$ moieties.

Analysis of the bond alternation $[24,26]$ in compounds 4 [23] and 5 [10] (crystalline state) shows that although the sum of differences between the longest bond and residual
Scheme 2 Formulas of the compounds studied and numbering of heavy atoms in their molecules

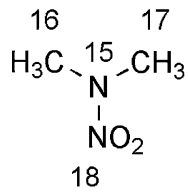

1

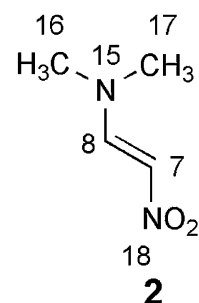

2

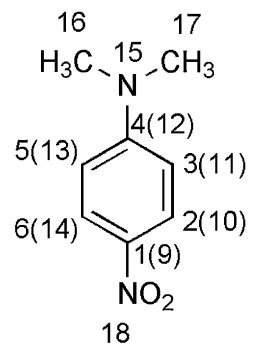

3
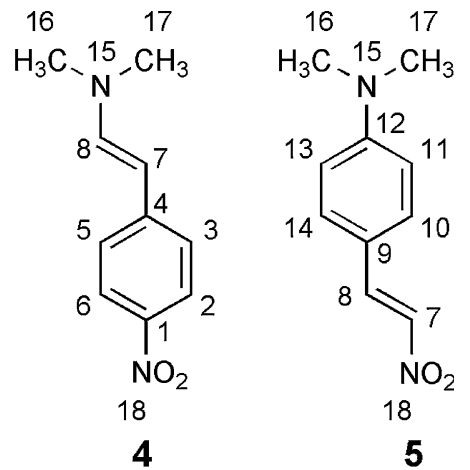
Table 1 X-ray bond lengths $[\mathrm{pm}]$ in $\mathbf{2 - 5}$

\begin{tabular}{lclll}
\hline Bond & $\mathbf{2}[22]$ & $\mathbf{3}$ & $\mathbf{4}[23]^{\mathrm{a}}$ & $\mathbf{5}[10]$ \\
\hline C7-C8 & 134.5 & - & 134.8 & 133.6 \\
& & & 135.4 & \\
C4-N15, C8-N15 & 133.4 & $135.8[19]$ & 135.9 & 135.95 \\
or C12-N15 & & $135[20]$ & 135.1 & \\
C1-N18 & 139.4 & $143.6[19]$ & 143.6 & 143.13 \\
or C7-N18 & & $140[20]$ & 144.6 & \\
C1-C2 & - & $138.9[19]$ & 138.9 & 140.57 \\
or C9-C10 & & $140[20]$ & 138.3 & \\
C2-C3 & - & $137.1[19]$ & 137.8 & 137.3 \\
or C10-C11 & & $137[20]$ & 129.5 & \\
C3-C4 & - & $141.9[19]$ & 139.3 & 142.3 \\
or C11-C12 & & $143[20]$ & 141.7 & \\
C4-C5 & - & $141.2[19]$ & 141.2 & 141.8 \\
or C12-C13 & & $143[20]$ & 141.1 & \\
C5-C6 & - & $137.8[19]$ & 139.2 & 139.0 \\
or C13-C14 & & $137[20]$ & 139.5 & \\
C6-C1 & - & $139.3[19]$ & 139.2 & 140.45 \\
or C14-C9 & & $140[20]$ & 144.7 & \\
\hline
\end{tabular}

${ }^{a}$ Data for different molecules present in the unit cell

bonds in the benzene ring are comparable (12.6 pm for $\mathbf{4}$ and $12.3 \mathrm{pm}$ for $\mathbf{5}$ ), differences between the $\mathrm{C}_{\mathrm{Ar}}-\mathrm{C}_{\mathrm{exo}}$ and $\mathrm{C} 7=\mathrm{C} 8$ bond lengths are much more differentiated $(0.3 \mathrm{pm}$

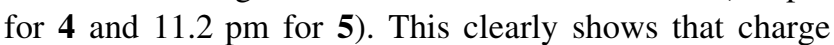
transfer in $\mathbf{4}$ is much more effective than in $\mathbf{5}$.

As this can be seen in Table 2, C16N15C17 valence angles in $\mathbf{2}, \mathbf{3}, \mathbf{4}$, and $\mathbf{5}$ are comparable. On the other hand, this angle in $\mathbf{1}$ is significantly larger. The O18N18O18 valence angle in $\mathbf{1}$ is also visibly larger than these in $\mathbf{2 , 3 , 4}$, and $\mathbf{5}$.

Sums of the bond angles around the amine nitrogens in 2

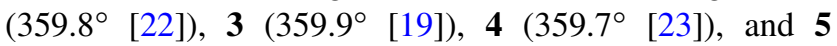
$\left(359.2^{\circ}[10]\right)$ reveal that these atoms are not fully $s p^{2}$ hybridized. The nitro groups in the molecules of compounds $\mathbf{1}$ [24, 25], 2 [22], and 4 [23] (crystal state) are always planar (sum of the bond angles around the nitro nitrogen is equal to $360.0^{\circ}$ ). Analysis of the bond lengths confirms that the charge transfer in $\mathbf{4}$ is much more

Table 2 X-ray bond angles $\left[{ }^{\circ}\right]$ in 1-5

\begin{tabular}{llllll}
\hline Angle & $\mathbf{1}$ & $\mathbf{2}[22]$ & $\mathbf{3}$ & $\mathbf{4}[23]$ & $\mathbf{5}[10]$ \\
\hline C16N15C17 & $124.6[25]$ & 117.0 & $118.7[19]$ & 117.2 & 118.7 \\
& $125.3[24]$ & & $118.2[20]$ & & \\
& $127.6^{\mathrm{a}}[18]$ & & & & \\
ON18O & $124.0[25]$ & 120.8 & $121.4[20]$ & 122.7 & 122.5 \\
& $124.0[24]$ & & & & \\
& $130.4^{\mathrm{a}}[18]$ & & & & \\
\hline
\end{tabular}

${ }^{\mathrm{a}}$ Electron diffraction data (gas state) effective than in 5. It is also proved by sum of the angles around the amino nitrogen being equal to $359.7^{\circ}$ in the molecule of 4 [23] and $359.2^{\circ}$ in the molecule of 5 [10] (sums of the angles around the nitro nitrogen atoms in these molecules are equal to $\left.360.0^{\circ}[10,23]\right)$.

The ortho hydrogen atoms are known to interact sterically with these present at the $\alpha$ position in styrene and stilbene or with those at the ortho positions of another benzene ring in biphenyl [27-32]. Such an interaction is expected to be insensitive to the charge transfer (Scheme 3). On the other hand, number of steric interactions between hydrogen atoms in the charge-transfer resonance forms of the compounds studied seems to be responsible for differences between them. Thus, crowding in $\mathbf{2}$ resembles this in $\mathbf{4}$. On the other hand, compounds 3 and $\mathbf{5}$ are of different type (Scheme 4). In consequence, loss of the charge by N15 in $\mathbf{2}$ is more easy than that in $\mathbf{4}$ and $\mathbf{5}$.

Increased multiplicity of the $\mathrm{Me}_{2} \mathrm{~N}-\mathrm{C}$ bond in the compounds studied indicated also by its length (see X-ray and electron diffraction in Table 1) is a result of the intramolecular charge transfer (Scheme 5). Hindering of free rotation of the dimethylamino group in $\mathbf{2 , 4}$, and $\mathbf{5}$ may result in non-equivalency of two $N$-methyl groups. ${ }^{1} \mathrm{H}$ and ${ }^{13} \mathrm{C}$ NMR spectral data [33] show that it is the case in compound $\mathbf{2}$ only. Thus, charge transfer in its molecule is much more effective than this in $\mathbf{4}$ and $\mathbf{5}$. The literature $\mathrm{X}$-ray data show that $\mathrm{Me}_{2} \mathrm{~N}-\mathrm{C}$ bond in 2 [22] is really much shorter than this in $\mathbf{3}$ [19, 20], 4 [23], and $\mathbf{5}$ [10] (the lengths of this bond in $\mathbf{3}, \mathbf{4}$, and $\mathbf{5}$ are comparable). Nonequivalent $N$-methyl groups were also found in some related compounds. Thus, due to increased contribution of the $p^{-}{ }^{-} \mathrm{O}_{2} \mathrm{~N}=\mathrm{C}_{6} \mathrm{H}_{4}=\mathrm{N}-\mathrm{CH}=\mathrm{N}^{+} \mathrm{Me}_{2}$ quinoid form, two different ${ }^{1} \mathrm{H}$ signals of the $N$-methyl protons are seen in the NMR spectrum of $\mathrm{N}, \mathrm{N}$-dimethyl- $\mathrm{N}$-(4-nitrophenyl)formamidine below the coalescence temperature [34].

Natural population analysis (NPA) $[35,36]$ seems useful to show the character and effectiveness of the intramolecular charge transfer in the compounds studied. The calculated NPA charges at the nitrogen atoms (Table 3) show that amount of the charge at N15 in compound $\mathbf{1}$ is much lower than in other compounds studied (it is almost constant in compounds 2-5). Notwithstanding two positively

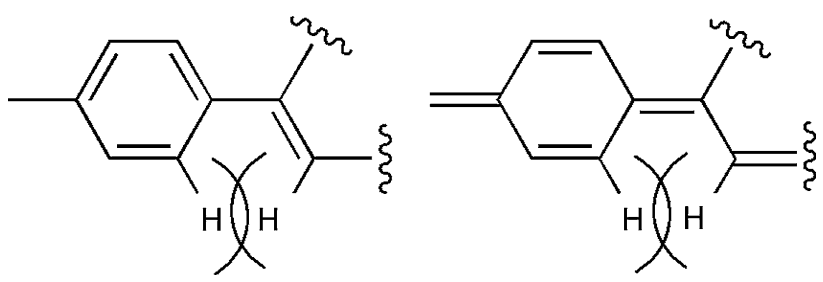

Scheme 3 Steric interactions in styrenes 

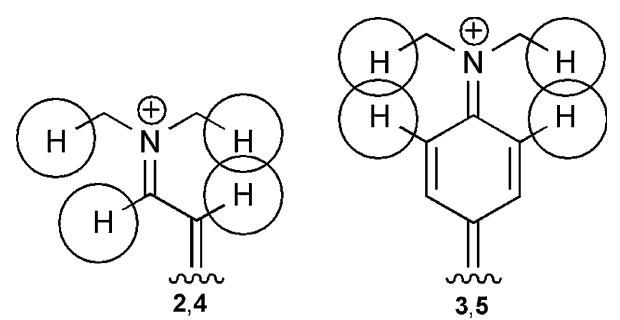

Scheme 4 Steric interactions in the molecules of compounds 2-5

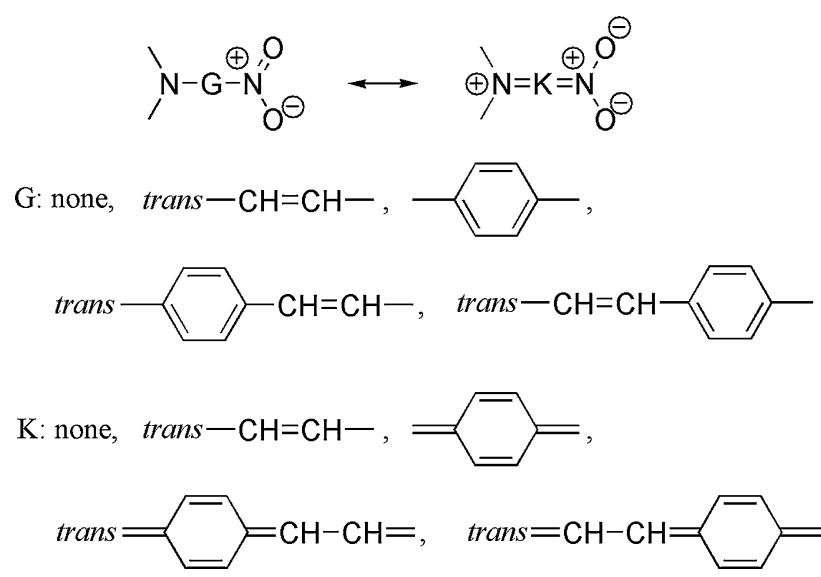

Scheme 5 Charge transfer in different $N$-nitroamines

charged nitrogen atoms in $\mathbf{1 b}$ (Scheme 6) are bound to each other, contribution of that resonance structure seems to be higher than that of 1c. Non-equivalency of the nitro oxygen atoms (see NPA charges in Table 3) being a result of the restricted rotation around selected bonds in the molecules of some compounds studied seems noteworthy. As this can be seen in Table 3, except O18 and N15 other atoms that accept the negative charge lost by $\mathrm{N} 15$ in the molecules of compounds $\mathbf{2 - 5}$ are C3, C5, C7, C9, C10, $\mathrm{C} 11, \mathrm{C} 13$, and C14. Relatively high NPA values for the methyl carbon atoms, $\mathrm{C} 16$ and $\mathrm{C} 17$, are also noteworthy.

Electron-withdrawing ability of the nitro group in a series of nitrobenzenes seems to be independent on substituent. Mulliken population analysis of the total and $\pi$ electron densities at the nitro oxygen and nitrogen atoms in such compounds was really found independent on substitution $[35,37]$. The calculated NPA charges at N18 and O18 (Table 3) show this to be the rule also for compounds

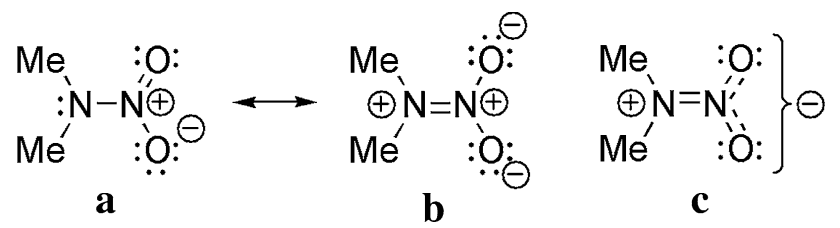

Scheme 6 Charge transfer in the molecule of $N, N$-dimethylnitroamine
Table 3 NPA charges at the heavy atoms in compounds 1-5 (in vacuum)

\begin{tabular}{llllll}
\hline Atom & $\mathbf{1}$ & $\mathbf{2}$ & $\mathbf{3}$ & $\mathbf{4}$ & $\mathbf{5}$ \\
\hline $\mathrm{C} 1$ & - & - & -0.026 & 0.003 & - \\
C2 & - & - & -0.134 & -0.161 & - \\
C3 & - & - & -0.323 & -0.252 & - \\
C4 & - & - & 0.282 & 0.016 & - \\
C5 & - & - & -0.323 & -0.257 & - \\
C6 & - & - & -0.134 & -0.162 & - \\
C7 & - & -0.286 & - & -0.388 & -0.163 \\
C8 & - & 0.167 & - & 0.122 & -0.087 \\
C9 & - & - & - & - & -0.189 \\
C10 & - & - & - & - & -0.129 \\
C11 & - & - & - & - & -0.310 \\
C12 & - & - & - & - & 0.269 \\
C13 & - & - & - & - & -0.319 \\
C14 & - & - & - & - & -0.128 \\
N15 & -0.351 & -0.531 & -0.537 & -0.543 & -0.538 \\
C16 & -0.431 & -0.404 & -0.413 & -0.406 & -0.413 \\
C17 & -0.431 & -0.423 & -0.413 & -0.421 & -0.413 \\
N18 & 0.765 & 0.611 & 0.626 & 0.624 & 0.604 \\
O18 & -0.473 & -0.471, & -0.467 & -0.463 & -0.461, \\
& & $-0.504^{\mathrm{a}}$ & & & -0.479 \\
\hline & & & & &
\end{tabular}

NPA natural population analysis

${ }^{a}$ Nitro oxygen atoms are not equivalent due to restricted rotation around some bonds in the molecule

3 and 4 (these compounds are substituted nitrobenzenes). The nitro group attached to the benzene ring seems to withdraw a constant electron density regardless the ring is electron rich or electron deficient [37]. Shortening of the C1-N18 bonds in the molecules of compounds 3 and 4 (Table 1), as compared with the averaged $\mathrm{C}_{\mathrm{Ar}}-\mathrm{NO}_{2}$ distances [21], supports the nitro group in nitroarenes to be really conjugated with the aromatic moiety.

\section{Conclusions}

X-ray and electron diffraction structural data show that significant amount of the charge from the amino nitrogen atom in $\mathrm{N}, \mathrm{N}$-dimethylnitramine (1), $\mathrm{N}, \mathrm{N}$-dimethyl-2-nitroethenamine (2), $N, N$-dimethyl- $p$-nitroaniline (3), 4-nitro- $\beta$ - $N, N$ dimethylaminostyrene (4), and 4- $N, N$-dimethylamino- $\beta$ nitrostyrene (5) was transferred to the nitro group. In general, effectiveness of the charge transfer changes in the following order: $\mathbf{1}>\mathbf{2}>\mathbf{3}>\mathbf{4}>\mathbf{5}$. Evaluation of this effect is based mainly on the bond lengths (bond angles are less useful). More severe steric interactions between the ortho and $\alpha$ hydrogen atoms in $\mathbf{5}$, with respect to these in $\mathbf{4}$, are responsible for more effective charge transfer in the later 
compound. The calculated NPA charges (Natural Population Analysis) at the amino and nitro nitrogen atoms show that amount of the charge at the former in compound $\mathbf{1}$ is much lower than in other compounds studied (it is almost constant in compounds 2-5). Except the nitro oxygens, other atoms that accept the negative charge lost by the amino nitrogen in the molecules of compounds $\mathbf{2}-\mathbf{5}$ are the vinylene, benzene as well as methyl carbons. The calculated NPA charges at the nitro nitrogen and oxygen atoms in compounds $\mathbf{3}$ and $\mathbf{4}$ show electron-withdrawing ability of the nitro group in substituted nitrobenzenes to be independent on substituent (nitro group attached to the benzene ring seems to withdraw a constant electron density regardless the substitution). Shortening of the $\mathrm{C}_{\mathrm{Ar}}-\mathrm{N}_{\text {nitro }}$ bonds in compounds $\mathbf{3}$ and $\mathbf{4}$ (as compared with the averaged $\mathrm{C}_{\mathrm{Ar}}-\mathrm{NO}_{2}$ distances) supports the nitro group in these nitroarenes to be really conjugated with the aromatic moiety.

\section{Computational details}

Natural population analysis [35, 36] was performed with Gaussian 03 [38] with use of MP2/6-31G(2d,p) method. Molecular geometries were optimized at the B3LYP/ 6-31G(2d,p) level (no intermolecular interactions were considered). The frequencies were calculated to make sure that geometry is in the energy minimum (no imaginary frequencies).

Acknowledgments We are very much indebted to the ACK CYFRONET AGH, Kraków (MNiSW/SGI3700/UTPBydg/042/2007) and CI TASK Gdańsk, for supply of computer time and providing programs.

Open Access This article is distributed under the terms of the Creative Commons Attribution Noncommercial License which permits any noncommercial use, distribution, and reproduction in any medium, provided the original author(s) and source are credited.

\section{References}

1. Staab HA (1962) Einführung in die Theoretische Organishe Chemie, Chapter 3. Verlag Chemie, Weinheim

2. Gawinecki R, Stanovnik B, Valkonen A, Kolehmainen E, Ośmiałowski B, Dobosz R, Zakrzewska A (2009) Struct Chem 20:655

3. Lee JY, Kim KS, Mhin BJ (2001) J Chem Phys 115:9484

4. Stals J (1969) Aust J Chem 22:2505

5. Sz Roszak (1994) J Mol Struct (THEOCHEM) 304:269

6. White MG, Colton RJ, Lee TH, Rabalais JW (1975) Chem Phys 8:391

7. Duke BJ (1978) J Mol Struct 50:109
8. Lopatin BV (1977) Theor Exp Chem 13:530

9. Lopatin BV (1977) Theor Exp Chem 13:399

10. Hamdellou L, Hernandez O, Meinnel J (2006) Acta Cryst C62:0557

11. Wheland GW (1955) Resonance theory in organic chemistry. Wiley, New York

12. Pauling L (1960) The nature of the chemical bond, 3rd edn. Cornell University Press, Ithaca

13. Krygowski TM, Maurin J (1989) J Chem Soc Perkin Trans 2:695

14. Hiberty PC, Ohanessian G (1984) J Am Chem Soc 106:6963

15. von Nagi-Felsobuki E, Topson RD, Pollack S, Raft RW (1982) J Mol Struct 88:255

16. Reynolds WF, Dais P, MacIntyre DW, Topson RD, Marriott S, von Nagi-Felsobuki E, Raft RW (1983) J Am Chem Soc 105:378

17. Costain W, Cox EG (1947) Nature (London) 160:826

18. Stølevik R, Rademacher P (1969) Acta Chem Scand 23:672

19. Borbulevych OYa, Clark RD, Romero A, Tan L, Antipin MYu, Nesterov VN, Cardelino BH, Moore CE, Sanghadasa M, Timofeeva TV (2002) J Mol Struct 604:73

20. Mak TCW, Trotter J (1965) Acta Cryst 18:68

21. Allen FH, Kennard O, Watson DG, Brammer L, Orpen AJ, Taylor R (1987) J Chem Soc Perkin Trans 2:S1

22. Hazell A, Mukhopadhyay A (1980) Acta Cryst B36:747

23. Tishkov AA, Dilman AD, Faustov VI, Birukov AA, Lysenko KS, Belyakov PA, Ioffe SL, Strelenko YuA, Antipin My (2002) J Am Chem Soc 124:11358

24. Filhol A, Bravic G, Rey-Lafon M, Thomas M (1980) Acta Cryst B36:575

25. Krebs B, Mandt J, Cobbledick RE, Small RWH (1979) Acta Cryst B35:402

26. Marder SR, Beratan DN, Cheng LT (1991) Science 252:103

27. Hallas G (1965) Organic stereochemistry. McGraw-Hill, London

28. Zaraiskii AP (1978) Usp Khim 47:847

29. Johansson MP, Olsen J (2008) J Chem Theory Comput 4:1460

30. Finder CJ, Newton MG, Allinger NL (1974) Acta Cryst B30:411

31. Traetteberg M, Frantsen EB, Mijlhoff FC, Hoekstra A (1975) J Mol Struct 26:57

32. ChH Choi, Kertesz M (1997) J Phys Chem A 101:3823

33. Gawinecki R, Kolehmainen E, Dobosz R, Chandrasekaran S, in preparation

34. Marsh JP, Goodman L (1967) Tetrahedron Lett 683-688

35. Benington F, Morin RD, Clark LC (1956) J Am Chem Soc 21:1470

36. Reed AE, Curtiss LA, Weinhold F (1988) Chem Rev 88:899

37. Lipkowitz KB (1982) J Am Chem Soc 104:2647

38. Frisch MJ, Trucks GW, Schlegel HB, Scuseria GE, Robb MA, Cheeseman JR, Montgomery JA Jr, Vreven T, Kudin KN, Burant JC, Millam JM, Iyengar SS, Tomasi J, Barone V, Mennucci B, Cossi M, Scalmani G, Rega N, Petersson GA, Nakatsuji H, Hada M, Ehara M, Toyota K, Fukuda R, Hasegawa J, Ishida M, Nakajima T, Honda Y, Kitao O, Nakai H, Klene M, Li X, Knox JE, Hratchian HP, Cross JB, Bakken V, Adamo C, Jaramillo J, Gomperts R, Stratmann RE, Yazyev O, Austin AJ, Cammi R, Pomelli C, Ochterski JW, Ayala PY, Morokuma K, Voth GA, Salvador P, Dannenberg JJ, Zakrzewski VG, Dapprich S, Daniels AD, Strain MC, Farkas O, Malick DK, Rabuck AD, Raghavachari K, Foresman JB, Ortiz JV, Cui Q, Baboul AG, Clifford S, Cioslowski J, Stefanov BB, Liu G, Liashenko A, Piskorz P, Komaromi I, Martin RL, Fox DJ, Keith T, Al-Laham MA, Peng CY, Nanayakkara A, Challacombe M, Gill PMW, Johnson B, Chen W, Wong MW, Gonzalez C, Pople JA (2004) Gaussian 03 revision E01. Gaussian Inc, Wallingford 